\title{
Identidade dos cursos de licenciatura e bacharelado em Educação Física no Paraná: uma análise das áreas do conhecimento
}

CDD. 20.ed. 371.12

375

http://dx.doi.org/10.1590/1807-55092014000400671
Juliana PIZANI ${ }^{*}$

Ieda Parra BARBOSA-RINALDI*
*Centro de Ciências da Saúde, Universidade Estadual de Maringá.

\section{Resumo}

Esta pesquisa do tipo descritiva objetivou identificar na matriz curricular de cursos de educação física a distribuição da carga horária por área do conhecimento, com vistas ao entendimento de como a formação se caracteriza no Paraná, especialmente quanto à existência de características próprias para os cursos de licenciatura e bacharelado. Para tanto, analisamos 28 projetos pedagógicos por meio de análise documental, na qual categorizamos as disciplinas presentes na matriz curricular por áreas/dimensões do conhecimento (formação específica e ampliada) propostas pela Resolução CNE/CES n.7/2004. Mediante os resultados encontrados, observamos que a formação específica agrega uma maior carga horária e um maior quantitativo de disciplinas, tendo como principal representante a dimensão cultural do movimento humano, que apresentou a maior carga horária tanto para os cursos de licenciatura como para os de bacharelado, o que condiz com os preceitos para a formação inicial em educação física, visto que abarca os conhecimentos identificadores que possuem tradição histórica da área. Identificamos também que os cursos possuem uma identidade própria relativa que os caracterizam como licenciatura e bacharelado, posto que a dimensão didático-pedagógica tem maior destaque na formação de licenciados e a técnicoinstrumental na de bacharéis. As dimensões pertencentes à formação ampliada receberam o mesmo grau de importância para ambas as formações. Contudo, alertamos para a necessidade de realização de outras pesquisas que possam subsidiar novas discussões e intervenções para a área, sobretudo porque a reformulação curricular que determinou a separação em licenciatura e bacharelado é muito recente.

Palavras-Chave: Currículo; Formação; Ensino; Intervenção.

\section{Introdução}

$\mathrm{Na}$ última década, a formação inicial em educação física tem passado por um processo de constantes transformações, em virtude do estabelecimento de novas Diretrizes Curriculares Nacionais (DCNs) que consigna uma diferente configuração para a área mediante reestruturação curricular, orientadas pelas Resoluçóes CNE/CP n. 1 e 2/2002 (licenciatura) ${ }^{1-2}$ e CNE/CES n. 7/2004 (bacharelado) .

Tendo como base as DCNs (Resoluções CNE/ CP n.1 e 2/2002) ${ }^{1-2}$, os currículos dos cursos de licenciatura precisam levar em consideração a formaçâo específica relacionada às diferentes etapas da educação básica, e ainda requerem a sua inserção no debate contemporâneo mais amplo, envolvendo questóes culturais, sociais e econômicas, como conhecimentos sobre o desenvolvimento humano e a própria docência. Nessa direção, Gimeno SACRISTÁN ${ }^{4}$ aponta que, ao mesmo tempo em que se busca atender aos aspectos legais, também se faz importante pensar em uma abordagem curricular comprometida com a emancipação humana e que não se distancie da realidade na qual está inserida.

Autores como Apple 5 e Gimeno Sacristán 6 , expõem uma visão crítica acerca da sua constituiçẫo nos contextos em que são consolidados, sendo mister a compreensão das relaçóes estabelecidas e das suas formas de institucionalização, com vistas a superar a concepção puramente burocrática e racional de ordenamento do ensino. Destarte é imprescindível reconhecer o currículo como um objeto social e histórico inserido num processo em constante transformaçáo e que, portanto, carece acompanhar a dinâmica social. 
Marcon et al. ${ }^{7}$ acrescentam que, também na educação física, muitos estudos evidenciam "a necessidade de levar os estudantes-professores a conhecerem e a se depararem, desde cedo na sua formaçáo inicial, com dilemas e situações-problema inerentes à intervenção docente e profissional dos professores" (p.498).

Para tanto, a Resolução CNE/CP n.2/2002 2 institui 2800 horas como carga horária mínima dos cursos de Formação de Professores da Educação Bási$\mathrm{ca}$, incluindo, neste caso, o curso de licenciatura em educação física, abarcando nesse tempo de integralização a articulação teoria-prática que deve se fazer presente no projeto pedagógico. Esta resolução ainda determina que o curso de licenciatura precisa destinar 400 horas de prática como componente curricular (vivenciadas ao longo de todo o curso), 400 horas de estágio curricular supervisionado (vivenciado a partir do início da segunda metade do curso), 1800 horas para os conteúdos curriculares e 200 horas para outras atividades acadêmico-científico-culturais ${ }^{2}$.

Já os currículos dos cursos de bacharelado em educação física são orientados pela Resolução CNE/CES n. $7 / 2004^{3}$ que traz orientaçóes de como os currículos devem ser construídos. Informa que estes necessitam atender as demandas da formação ampliada e específica, sendo que a primeira abrange as dimensóes do conhecimento no tocante à relação ser humanosociedade, biológica do corpo humano e produção do conhecimento científico e tecnológico, objetivando possibilitar uma formação cultural abrangente que contribua para a futura atuação profissional, mantendo um diálogo com as demais áreas do conhecimento. A segunda trata dos conhecimentos identificadores da área da educação física, e contempla e articula as dimensóes cultural do movimento humano, técnicoinstrumental e didático-pedagógica, buscando qualificar e habilitar o profissional de educaçáo física em função dos campos de intervenção ${ }^{3}$.

Buscando garantir a efetivação dessas dimensões, em relação à carga horária mínima do curso de bacharelado em educação física, a Resolução CNE/ CES n. $4 / 2009^{8}$ estabelece 3200 horas, em que os estágios e as atividades complementares não poderão exceder $20 \%$ da carga horária total do curso, e junto com a prática como componente curricular, deverão assegurar a indissociabilidade entre teoria e prática.

Oliveira $^{9}$ destaca que esta nova configuração da área poderá possibilitar "uma maior satisfação aos anseios dos futuros participantes dos cursos, pois desde o início estaráo mais próximos das estruturas de intervenção que escolheram" (p.28), tanto no que se refere à licenciatura como ao bacharelado. Isso porque, de acordo com Freire e Verenger ${ }^{10}$ "na estrutura até entáo existente, o cumprimento das horas obrigatórias de estágio predominavam no último ano do curso e a supervisáo dessas horas acontecia em disciplina especialmente criada para esse fim" (p.116).

Em contrapartida, MARTINS e BRANDALISE ${ }^{11}$ ressaltam que na visão dos acadêmicos o estágio curricular supervisionado quando mal orientado/supervisionado não contribui com a aproximaçáo do futuro campo profissional. Em outra pesquisa realizada no Estado de São Paulo por Silva et al. ${ }^{12}$ é possível observar que, de fato o estágio curricular não tem acontecido com a devida supervisão. Acrescentam que as condiçóes de trabalho do professor orientador não favorecem o desenvolvimento dos aspectos pedagógicos, pois o papel deste tem sido muito mais burocrático e fiscalizador.

A partir das mudanças nas Diretrizes Curriculares para a formação na área da educação física, os cursos de licenciatura e bacharelado devem ser estruturados de forma que representem campos de atuação distintos e, portanto, formaçôes com características próprias.

Essa caracterização de acordo com Hunger et al. ${ }^{13}$ está diretamente relacionada com as novas exigências acerca do perfil profissional esperado pela sociedade. Mesmo considerando esta realidade, Anderáos ${ }^{14}$ aponta que, no processo formativo, é imperativo ponderar que "o mercado náo pode ser o balizador supremo da educaçáo, mas deve ser antecipado e visualizado como um dos componentes do panorama necessário que se tenha, quando se pensa a formaçáo em nível superior” (p.92).

Nesse sentido, as disciplinas presentes nas matrizes curriculares dos projetos pedagógicos, têm a incumbência de diferenciar e caracterizar os cursos de licenciatura e bacharelado, não somente pela nomenclatura instituída, mas pelos objetivos, ementas, referenciais, discussóes estabelecidas em sala de aula e carga horária de acordo com as áreas de conhecimento. Mediante os pressupostos apresentados, elegemos as seguintes questóes norteadoras: como foram organizados os currículos dos cursos de licenciatura e bacharelado em educação física no Estado do Paraná, no que diz respeito à distribuição da carga horária e área do conhecimento, após a promulgação das Resoluçóes CNE/CP n. $1^{1}$ e 2/2002 e CNE/CES n. $7 / 2004^{3}$ ? Atualmente, os cursos de licenciatura e bacharelado em educação física do Estado do Paraná apresentam formaçôes com características próprias?

Para responder a tais questionamentos, esta pesquisa teve por objetivo identificar na matriz curricular de cursos de educação física a distribuição da carga horária 
por área do conhecimento, com vistas ao entendimento de como a formação se caracteriza no Paraná, especialmente quanto à existência de características próprias para os cursos de licenciatura e bacharelado.

Procurando atender ao objetivo proposto, o presente texto foi estruturado em três partes. Inicialmente, apresentamos a metodologia selecionada para o desenvolvimento do estudo, na sequência discutimos os dados encontrados. Por fim, trazemos algumas consideraçóes acerca das ideias tratadas.

Espera-se que essa pesquisa venha contribuir para a visualização de possíveis repercussóes da implementação das novas Diretrizes Curriculares Nacionais (DCNs), fundamentalmente para verificar se há

\section{Método}

A presente pesquisa caracteriza-se como do tipo descritiva, por ter como objetivo a descrição das características de fatos ou fenômenos ${ }^{15}$. Para responder ao objetivo do estudo, contabilizamos, por meio da listagem disponibilizada pelo Ministério da Educação e Cultura ${ }^{16}$ no ano de 2014 (http://emec. mec.gov.br/) que atualmente o Paraná possui 43 IES que oferecem cursos de formação em educação física presencial e à distância, sendo o terceiro Estado mais representativo do país na oferta de cursos de educação física $(7,4 \%)$, estando atrás somente de São Paulo $(27,7 \%)$ e Minas Gerais (13\%).

Em seguida, selecionamos as IES participantes a partir do seguinte critério: oferecer os cursos de licenciatura e bacharelado em educação física conforme previsto nas Resoluçóes CNE/CP n. $1^{1}$ e 2/2002 ${ }^{2}$ e CNE/CES n.7/2004 ${ }^{3}$. Posteriormente, entramos em contato com os coordenadores do curso de educação física dessas instituiçóes para convidá-los a participar da pesquisa e para obter a autorizaçáo para a realização da mesma.

Inicialmente, atendendo ao critério de seleção, a amostra constituiu-se por seis IES públicas e 24 privadas, totalizando 30 Instituiçóes de Ensino Superior que possuem o curso de licenciatura e bacharelado em educação física. Dessas 30 IES, 20 aceitaram participar da pesquisa, mas devido à liberdade de desistência expressa no termo de consentimento livre e esclarecido assinado pelos participantes, a amostra reduziu-se para 14 instituiçóes (seis públicas e oito privadas) por não disponibilizarem a documentação requerida para análise. As instituiçôes participantes do estudo apresentaram boa avaliação, com notas acima de 3 no "ranking" do Índice Geral de Cursos. existência de características próprias para os cursos de licenciatura e bacharelado da área. Isto porque, com as novas DCNs, percebe-se o estabelecimento do fim da antiga licenciatura ampliada (formação para campo escolar e não escolar), e de uma nova configuração para a formação da área, o que justifica que estudos sejam realizados para identificar se as mudanças foram positivas e consolidadas.

Entretanto, vale informar que não adentraremos no campo da discussão sobre questóes de ordem políticoacadêmica relacionadas ao processo de divisão dos cursos na área da educação física, permeado pela influência do processo de regulamentação da profissão, dentre outras, posto que não é objeto do estudo em questão.

A composição da fonte de dados compreendeu os projetos pedagógicos (PP) dos cursos de licenciatura e bacharelado em educação física das IES do Estado do Paraná, num total de 28 PPs. A opção por esses projetos, como fonte de dados, decorreu do entendimento de que os mesmos seriam expressivos para a caracterização dos cursos de formação inicial e permitiria uma visão geral de como a educação física no ensino superior encontra-se estruturada após a reformulação curricular.

Para o tratamento dos dados encontrados nos projetos pedagógicos recorremos à análise documental que, segundo GIL ${ }^{15}$, trata-se de uma pesquisa que se desenvolve com base em materiais que ainda não receberam um tratamento analítico, sendo diversificadas e dispersas.

Também é importante evidenciar que o projeto pedagógico foi analisado dentro de suas peculiaridades, de acordo com as premissas da licenciatura e do bacharelado. Para tanto, fizemos um levantamento das disciplinas que compóem os dois currículos, as quais foram categorizadas, pelas autoras, de acordo com as áreas de conhecimento.

Como áreas de conhecimento, utilizamos a proposta de dimensóes do conhecimento presentes na Resolução CNE/CES n.7/2004³ : ser humanosociedade, biológica do corpo humano, produção do conhecimento científico e tecnológico, cultural do movimento humano, técnico-instrumental e didático-pedagógica. Ressaltamos que, mesmo expressas na Resolução CNE/CP n.1/2002 ${ }^{1}$, específica da licenciatura, orientaçôes para a organização curricular, optamos por categorizar 
as disciplinas de acordo com as dimensôes do conhecimento proposto pela Resolução CNE/CES n. $7 / 2004^{3}$, para assim termos um padrão único de comparação e entre as duas formaçôes. Isso também contribuiu para visualizarmos um quadro geral da constituição da matriz curricular das instituiçôes, permitindo identificar a existência de concentração de disciplinas em alguma dimensão em detrimento de outras.

\section{Resultados e discussão}

As análises realizadas foram feitas a partir das Resoluçóes CNE/CP n. $1^{1}$ e 2/2002 ${ }^{2}$ e CNE/CES n. $7 / 2004^{3}$ que estabelecem as novas diretrizes curriculares para a área, indicando que os currículos precisam apresentar formaçôes específicas para a licenciatura e bacharelado, oferecendo subsídios suficientes para uma atuação adequada nos diferentes campos de intervenção, seja ele escolar ou não-escolar.

Vale informar que, nesta pesquisa não adentraremos no campo de discussão sobre a legalidade que rege a área da educação física, a qual estabelece o fim da antiga licenciatura ampliada, visto que o intuito é verificar como a formação se encontra organizada após a sanção das resoluçóes que orientam as novas diretrizes.

Optamos por fazer uma análise da organização curricular a partir do proposto pela Resoluçáo CNE/ CES n.7/2004 ${ }^{3}$, em que traz que a constituição de um currículo necessita atender as dimensões da formação ampliada (relação ser humano-sociedade, biológica do corpo humano e produção do conhecimento) e da formação específica (cultural do movimento humano, técnico-instrumentais e didático-pedagógicas). Faz-se pertinente ressaltar que essa Resoluçãa ${ }^{3}$ estabelece as dimensóes do conhecimento como orientação para a
Para fazer essa distribuição recorremos ao projeto pedagógico, especialmente à matriz curricular e às ementas para confirmação dos conteúdos a serem tratados na disciplina. Contudo, a apresentação dessa listagem não será apresentada nesse texto, devido à extensáo do arquivo.

Salientamos que essa pesquisa foi aprovada pelo Comitê Permanente de Ética em Pesquisa envolvendo Seres Humanos (CONEP) sob Parecer n. 247/2010.

organização dos currículos, no entanto, não traz uma indicaçáo de percentual por área para essa distribuição.

Para tanto, realizamos um levantamento das disciplinas encontradas na matriz curricular dos projetos pedagógicos das IES participantes da pesquisa, as quais foram distribuídas por dimensão do conhecimento. Recorremos às ementas para ter maior confiabilidade nessa designação. Devido à extensão do arquivo, o quadro geral das disciplinas listadas foi sintetizado, e apresentamos apenas a carga horária total do curso e de cada área do currículo.

Seguem resultados do mapeamento realizado no tocante à organizaçáo curricular de 14 IES que oferecem os cursos de licenciatura e bacharelado em educação física no Estado do Paraná, com a média da carga horária total e de cada dimensão do conhecimento, bem como o percentual de cada uma delas.

Vale destacar que as instituiçóes públicas e privadas não apresentaram diferenças significativas na composição curricular quando comparadas e que devido a este fato optamos por acoplar os resultados em quadros únicos, pois não haveria alteração da média pela semelhança apresentada.

A FIGURA 1 segue com o comparativo entre os cursos de licenciatura e bacharelado. 
TABELA 1 - Média da distribuição da carga horária e percentual dos cursos de licenciatura em educação física de acordo com as dimensões do conhecimento.

\begin{tabular}{|c|c|c|}
\hline \multicolumn{3}{|c|}{ LICENCIATURA } \\
\hline \multicolumn{3}{|c|}{ Formaçáo ampliada } \\
\hline Dimensáo do conhecimento & Carga horária h/a & \% da dimensáo \\
\hline Relação ser humano-sociedade & 301 & 9,7 \\
\hline Biológica do corpo humano & 396 & 12,8 \\
\hline Produção do conhecimento científico e tecnológico & 209 & 6,7 \\
\hline Subtotal & 906 & 29,2 \\
\hline \multicolumn{3}{|c|}{ Formaçáo específica } \\
\hline Dimensáo do conhecimento & Carga horária h/a & \% da dimensão \\
\hline Culturais do movimento humano & 727 & 23,4 \\
\hline Técnico-instrumental & 606 & 19,5 \\
\hline Didático-pedagógico & 660 & 21,3 \\
\hline Subtotal & 1993 & 64,2 \\
\hline Atividades acadêmicas complementares & 203 & 6,5 \\
\hline Total & 3102 & 100 \\
\hline
\end{tabular}

TABELA 2 - Média da distribuição da carga horária e percentual dos cursos de bacharelado em educação física de acordo com as dimensões do conhecimento.

\begin{tabular}{|c|c|c|}
\hline \multicolumn{3}{|c|}{ LICENCIATURA } \\
\hline \multicolumn{3}{|c|}{ Formaçáo ampliada } \\
\hline Dimensáo do conhecimento & Carga horária h/a & \% da dimensáo \\
\hline Relação ser humano-sociedade & 305 & 9 \\
\hline Biológica do corpo humano & 536 & 16 \\
\hline Produção do conhecimento científico e tecnológico & 212 & 6 \\
\hline Subtotal & 1053 & 31 \\
\hline \multicolumn{3}{|c|}{ Formaçáo específica } \\
\hline Dimensáo do conhecimento & Carga horária h/a & \% da dimensáo \\
\hline Culturais do movimento humano & 890 & 26 \\
\hline Técnico-instrumental & 794 & 24 \\
\hline Didático-pedagógico & 436 & 13 \\
\hline Subtotal & 2120 & 63 \\
\hline Atividades acadêmicas complementares & 205 & 6 \\
\hline Total & 3378 & 100 \\
\hline
\end{tabular}




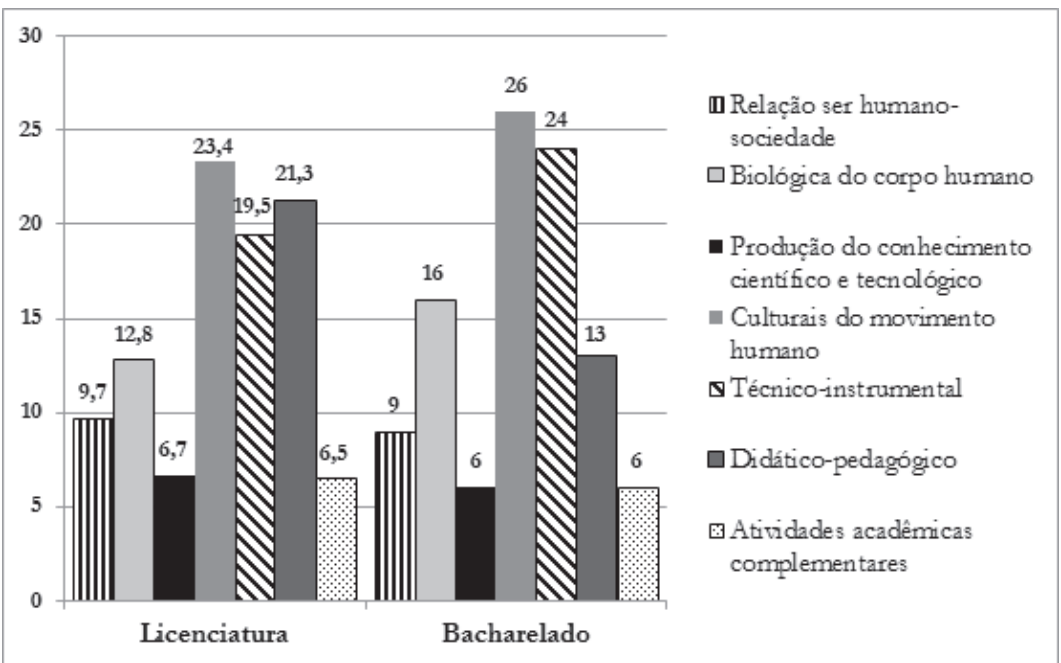

FIGURA 1 - Percentual de distribuição da carga horária das disciplinas dos cursos de licenciatura e bacharelado em educação física por dimensão do conhecimento e das atividades complementares como parte da carga horária total do currículo.

Ao analisar a carga horária total dos cursos de licenciatura e bacharelado presente nas TABELAS 1 e 2, a média constatada ultrapassa o mínimo estabelecido pelas Resoluçóes CNE/CP n.2/2002² e CNE/CES n.4/20098 que instituem 2800 horas para a licenciatura e 3200 horas para o bacharelado, ambas contabilizadas em hora relógio - 60 minutos. Desse modo, os resultados indicam que os cursos atendem aos dispostos legais referentes à carga horária mínima a ser oferecida.

Analisando mais especificamente as dimensóes destacadas, a que representa maior evidência é a cultural do movimento humano, com $23,4 \%$ da carga horária total do curso de licenciatura e $26 \%$ do bacharelado. Provavelmente isto se dê porque esta dimensão abarca os conhecimentos mais representativos da educaçáo física (jogos e brincadeiras, esportes, lutas, danças e ginásticas), e que são relacionados às manifestaçôes da cultura corporal de movimento. Além do mais, as disciplinas com este caráter, historicamente sempre ocuparam a maior carga horária dos cursos de educação física desde o primeiro curso civil do país, datado de 1939, contribuindo para a manutenção da tradiçẫo da área ${ }^{17}$. Este modelo de currículo centrado nas práticas esportivas perdurou até a promulgação da Resolução CFE $3 / 1987^{18}$ que pôs fim ao currículo mínimo.

A partir da década de 80 surgiram diversas nomenclaturas e bases teóricas diferentes para discutir o objeto de estudo da educação física, dentre elas movimento humano ${ }^{19}$, cultura corporal ${ }^{20}$, cultura corporal de movimento $^{21}$, cultura física ${ }^{22}$, e de acordo com SOARES ${ }^{23}$ existe um consenso de que os jogos e brincadeiras, danças, lutas, esportes e ginásticas são conhecimentos específicos da área. Isto porque não se pode ensinar sem que se tenha um conteúdo a ser ensinado e a cultura corporal de movimento é o que nos identifica ${ }^{24}$.

Sobre o assunto, especialmente para os cursos de licenciatura, como a pesquisa foi realizada com as instituiçôes de ensino superior do Paraná, também podemos citar as Diretrizes Curriculares da Educação Básica do Estado do Paraná - DCEs ${ }^{25}$, que baseadas em SOARES et al. ${ }^{20}$ apontam a cultura corporal como objeto de estudo da educaçáo física, e estabelecem os temas que compóem o universo de conhecimento da área, representados pelos conteúdos estruturantes (jogos e brincadeiras, esporte dança, lutas e ginástica). Vale destacar que os conteúdos estruturantes presentes nas DCEs são entendidos como "conhecimentos de grande amplitude, conceitos, teorias ou práticas, que identificam e organizam os campos de estudos de uma disciplina escolar, considerados fundamentais para a compreensão de seu objeto de estudo/ensino" ${ }^{25}$ (p.25).

Com referência a essa dimensão, no que concerne, sobretudo ao bacharelado, também citamos a Resolução CNE/CES n.7/2004 ${ }^{3}$ que em seu Artigo $3^{\circ}$ apresenta o movimento humano como objeto de estudo e de aplicação da educação física, tendo como foco as diferentes formas e modalidades do exercício físico, por exemplo, a ginástica, o jogo, o esporte, a luta/arte marcial e a dança. Estas manifestaçóes podem ser desenvolvidas em diferentes espaços de intervençáo, tendo como foco o treinamento, lazer, saúde e qualidade de vida, entre outros.

No tocante à dimensão didático-pedagógica, os resultados apontam um percentual de $21,3 \%$ para a licenciatura e $13 \%$ para o bacharelado. 
Esta dimensão contempla conhecimentos dos princípios gerais e específicos de gestão e organização das diversas possibilidades de intervenção do profissional no campo de trabalho e de formação, ocupando a segunda maior carga horária dos cursos de licenciatura e a terceira do curso de bacharelado, principalmente por agregar as disciplinas relacionadas ao estágio supervisionado.

Para a formação de professores, esta dimensão tem expressiva significância, tendo em vista que as disciplinas com esse caráter são imprescindíveis, pois irão tratar de questóes direta ou indiretamente relacionadas ao processo educacional escolar, oportunizando aos futuros professores conhecerem e analisarem criticamente o processo educacional e de construir um instrumental teórico-metodológico que possa sedimentar sua atuação docente.

Para Pimenta ${ }^{26}$ "os profissionais da educação, em contato com os saberes sobre a educaçáo e sobre a pedagogia, podem encontrar instrumentos para se interrogarem e alimentarem suas práticas" (p.26). Segundo a autora, os saberes da docência são construídos a partir de três categorias que viabilizam a ação de ensinar: saberes da experiência (conhecimentos advindos da própria experiência como aluno, da prática docente reflexiva, discussão com os pares etc.), conhecimento (abrange questóes da função da escola no ato de ensinar e suas especialidades) e saberes pedagógicos (abrange as duas primeiras categorias articulados aos conteúdos específicos, construído a partir das necessidades pedagógicas reais).

Entretanto, a formação inicial, em geral, é constituída de situações de ensino e aprendizagem descontextualizadas da atuação prática e, é por isso que a literatura consultada ${ }^{7,26-31}$ indica que a inclusão das práticas pedagógicas e do estágio supervisionado, concernentes à dimensão didático-pedagógica, na formaçáo inicial de professores, em forma de disciplinas ou componentes curriculares, pode contribuir com a aproximação teoria e prática docente, enriquecendo assim o processo formativo do futuro professor.

No entanto, a dimensão didático-pedagógica não é uma exclusividade da licenciatura, especialmente porque nos cursos pesquisados, tanto na licenciatura como no bacharelado, identificamos a presença da disciplina de estágio supervisionado com carga horária elevada comparada às demais disciplinas. Advertimos ainda que, algumas disciplinas como didática e psicologia da educação, que têm seus conteúdos voltados exclusivamente para o contexto educacional escolar, não são desenvolvidas nos cursos de bacharelado.
Sobre o assunto, Souza Neto et al..$^{32}$, Oliveira ${ }^{9}$ e NAscimento ${ }^{33}$ salientam ser fundamental ter uma formação voltada para os campos específicos de atuação. Nesse sentido, justifica-se a presença de disciplinas que abarcam conteúdos didáticopedagógicos voltados para os campos de intervenção também no bacharelado.

$\mathrm{Na}$ sequência aparece a dimensão técnico-instrumental, com 19,5\% da carga horária nos cursos de licenciatura e $24 \%$ no bacharelado. No curso de bacharelado esta dimensão se apresenta em segunda posição e no de licenciatura em terceira. Nota-se que houve uma inversão entre as dimensóes didático-pedagógica e técnico-instrumental, a primeira mais evidenciada na licenciatura e a segunda no bacharelado.

Esse fato demonstra que os cursos de formação em licenciatura concentram uma carga horária maior na área pedagógica para o atendimento da educação física escolar, enquanto o bacharelado, devido à necessidade de intervençáo nos demais campos de atuação, dedica um tempo maior à área instrumental.

Essa divergência entre as formaçōes se torna de certo modo coerente, visto que a dimensão técnicoinstrumental reúne conhecimentos sobre: as bases teóricas e metodológicas aplicadas ao desempenho humano, o desenvolvimento humano, o comportamento motor, a psicologia, a dinâmica e relaçóes estabelecidas no ensino, etc., que irão instrumentalizar o profissional para sua atuação. E no que se refere ao bacharelado, destaca-se por proporcionar aos alunos a compreensão e instrumentalização de diferentes áreas da educação física, essencial para a atuação nos diferentes campos não escolar.

Esses saberes, de acordo com Marcon et al. ${ }^{24}$ constituem-se como "conhecimentos identificadores da área (formação básica)” (p.413), especialmente os relacionados "ao corpo humano e seu desenvolvimento, bem como aqueles conhecimentos que oferecem suporte para a identificação dos interesses, das expectativas e das necessidades específicas de crianças, jovens, adultos, idosos, pessoas portadoras de deficiência e de grupos e comunidades especiais" (p.413).

Já na licenciatura, a presença desses conhecimentos, mesmo que com menos destaque que no bacharelado, justifica-se para contribuir com o entendimento sobre "as categorias do domínio motor: habilidades básicas, capacidades perceptivas, atividades rítmicas, comunicação não verbal, jogo, capacidades físicas e habilidades esportivas" ${ }^{34}$ (p.75).

A inversão de carga horária entre a licenciatura e o bacharelado no tocante às dimensões didáticopedagógica e técnico-instrumental, também 
demonstra que o tempo destinado às disciplinas caminha para a compreensão da diferenciação entre as duas formaçóes, as quais passam a abordar conhecimentos específicos dos distintos campos de atuação a que se destinam. A primeira se torna mais específica para a atuação escolar, enquanto a segunda destina-se para o atendimento dos demais espaços.

A partir destes resultados podemos aferir que os currículos analisados apresentaram características próprias para licenciatura e para o bacharelado e, portanto, configuram-se como distintos, aproximandose do que prevê as diretrizes curriculares nacionais. E, considerando a representatividade nacional do Estado do Paraná, que atualmente oferece 44 cursos de educação física, 7,4\% do cenário nacional, estes resultados podem contribuir para o entendimento da constituiçáo dos cursos de outras localidades, uma vez que possui caráter de generalização.

Não muito distante da citada anteriormente, temos a dimensão biológica do corpo humano, com $12,8 \%$ na licenciatura e $16 \%$ no bacharelado. As disciplinas que compóem essa dimensão subsidiam a atuação do professor, seja na escola ou fora dela, haja vista que permitem entender o movimento a partir dos aspectos biológicos, fisiológicos, anatômicos, biomecânicos, entre outros.

Outro ponto é a relação entre o conteúdo biológico e a promoçáo e/ou manutenção da saúde alcançada por meio da atividade física. Temática que tem sido foco de discussóes na área da educação física, sobretudo relacionada aos espaços de intervenção específicos do bacharelado. De acordo com BAgRichevsky e PALMA $^{35}$, os aspectos fisiológicos parecem ainda ser mais explorados nos estudos sobre saúde nesse contexto comparados a outros enfoques. Ainda de acordo com os mesmos autores, a relaçáo predominante nessa tendência "é a da atividade física associada à saúde, a qual vem sendo enunciada, com freqüência, como fenômeno de 'causa e efeito'; ou seja, a saúde entendida como conseqüência quase exclusiva da prática regular de atividades físicas" (p.58).

Em contrapartida, Nogueira e PALMA ${ }^{36}$ afirmam que a saúde é consequência de uma multiplicidade de aspectos, que são resultantes de condições relacionadas à alimentação, habitação, trabalho, educaçáo, lazer, acesso aos serviços de saúde, entre outras.

Corroborando com a ideia, mas especificamente para os cursos de licenciatura, as Diretrizes Curriculares da Educação Básica do Estado do Paraná trazem o elemento articulador cultura corporal e saúde, o qual permite entendê-la como uma dimensão históricosocial, rompendo com a tendência dominante de concepção de saúde como simples aspiração individual. E com base nisso propóem elementos considerados como constitutivos da saúde: nutriçáo, lesôes e primeiros socorros, aspectos anátomofisiológicos da prática corporal e "doping"25.

Assim, com base em Devide ${ }^{37-38}$, o professor deve relacionar os conhecimentos tratados na educação física com a realidade de seus alunos, e estar ciente da concepção equivocada no que tange a educaçáo física como promotora de saúde. Faz-se imperioso a apropriaçáo do conceito multifatorial de saúde, anteriormente descrito, e sua dimensão social, pois, o educador provido de instrumentação teórica consistente, poderá tecer discussóes que superem o paradigma hegemônico da aptidáo física, tornando-se uma via de educação para a saúde dos alunos, para que esses, frente às suas condiçóes de vida, tenham uma postura crítica que contribuirá para a desmistificação da visão equivocada existente entre o exercício físico e a saúde. Assim, a base teórica advinda das disciplinas, presentes na dimensão biológica, associada às outras dimensôes do currículo poderá permitir o aporte necessário à atuação do professor/profissional de educação física. Dessa forma, justifica-se a presença de conhecimentos vinculados à dimensão biológica do corpo humano tanto nos cursos de bacharelado como nos de licenciatura.

Outra dimensão é a relação ser humano-sociedade, que apresentou $9,7 \%$ nos cursos de licenciatura e 9\% nos de bacharelado. Esta compreende os conhecimentos históricos, sociológicos, ético-políticos, filosóficos, religiosos e culturais, os quais tangem a formação do profissional de educação física referendados pelo conhecimento do homem na sociedade.

Esta recebeu influências de professores da área que realizaram cursos de pós-graduação na educação, principalmente após década de 80 . Nesse mesmo período, também por influência dos pesquisadores da área, foi homologada a Resolução CFE n.3/1987 $7^{17}$, que fundamentou a distribuição dos saberes em formação geral (humanística e técnica) e aprofundamento de conhecimentos, defendendo que o egresso deveria ter um forte embasamento nas ciências humanas, uma vez que, o Parecer CNE/CES n. $215 / 1987^{39}$ considera a educação física como atividade física, que dentro do contexto geral da educaçáo pelo movimento, envolve o ser humano e a sociedade independente da ênfase que lhe for atribuída. Desse modo, os cursos, tanto de licenciatura como de bacharelado, parecem manter a tradição construída da presença de tal dimensão nos cursos da área.

Segundo BARros ${ }^{34}$, o professor precisa ter uma visão da função social da escola, bem como de sua 
história, dos problemas que a envolvem e as perspectivas que se tem para a sociedade, compreendendo o papel e os objetivos da educaçáo física no contexto escolar. Isso também se aplica ao contexto do bacharelado, pois ambas as formações terão contato direto com o aspecto social, em que as atividades desenvolvidas requerem articulaçáo com o conhecimento do ser humano, da sociedade, da realidade, além dos saberes técnicos e humanísticos também necessários.

Outra dimensão ainda a ser levada em consideração na formação é a produçáo do conhecimento tecnológico e científico, que representa $6,7 \%$ da carga horária dos cursos de licenciatura e $6 \%$ dos cursos de bacharelado. A produção de conhecimento encontra-se atrelada à realização de pesquisas que lançam novos conhecimentos no mundo acadêmico e comunitário. Pode ser entendida a partir das aplicaçôes dos conhecimentos de comunicação acadêmica escrita e oral da língua portuguesa, da informática e dos conhecimentos básicos de estatística relacionada à atuação profissional em educação física.

$O$ que se percebe na formaçáo inicial das IES participantes da amostra, é que essa dimensão agrega disciplinas que incentivam o acadêmico a produzir conhecimento, principalmente por meio da elaboração de um trabalho de conclusão de curso. Podemos observar que, de 14 IES participantes somente quatro oferecem cursos de pós-graduação "stricto sensu". Assim, a produçáo de conhecimento com a caracterização de pesquisa científica embasada por um sistema que busca dar suporte para seu desenvolvimento ainda é minoria.

No entanto, é notório que a produção de conhecimento requer um sólido sistema de pesquisa e desenvolvimento, bem como um corpo de pesquisadores preparados para se responsabilizar pelas pesquisas ${ }^{40}$ e que, por vezes, centraliza-se na pós-graduação. Isso porque, de acordo com o autor, o processo de formação na pós-graduação ocorre paralelamente à produção de novos conhecimentos que é potencializado pelo engajamento discente (futuros mestres e doutores).

A pós-graduação, mesmo sendo um componente paralelo, está diretamente relacionada com a graduação e com a pesquisa. Segundo КоковuN ${ }^{40}$, tanto a graduação como a pesquisa náo se desenvolvem isoladamente, pois a pesquisa apresentase como principal instrumento para a produção, aperfeiçoamento e renovação de um corpo de conhecimentos com densidade e profundidade. Este corpo de conhecimento justifica a criação e manutenção de um curso de graduação, constituindo a base de todo o processo de formação superior.
Esta condiçáo justifica o fato de que a produção científica também deve ser fomentada na graduação, o que refletirá na atuação profissional nos diferentes campos de intervenção da área, seja na licenciatura ou no bacharelado, haja vista a importância de romper com a unilateralidade e hierarquia da produção de conhecimento pelos pesquisadores inseridos em programas de pós-graduação, assim como no ensino superior, pois outros níveis de ensino náo podem apenas receber e repassar, é preciso que se analise criticamente o que está posto, e também pesquisem e produzam novos saberes, buscando alternativas para as lacunas encontradas.

Essa formação de atitude crítica passa pela apropriação do conhecimento já produzido, mas também depende do exercício e entendimento do processo para se construir, e a partir de entáo, tem a possibilidade de identificar problemas e sugerir intervençôes. $\mathrm{E}$ de acordo com Demo ${ }^{41}$, a manipulação e a produção do conhecimento fortalecem os sujeitos históricos, pois a partir disso os indivíduos adquirem capacidade crítica e criativa para a própria emancipação.

Por fim, Barbosa-Rinaldi ${ }^{42}$ indica que o currículo é caracterizado pelos atores envolvidos em sua elaboraçáo. Partindo deste pressuposto, inferimos que o direcionamento que se dá à formação tem muita relação com as características da instituição, bem como com os professores envolvidos, em que cada um busca assegurar, nesse contexto, sua área de atuação e/ou pesquisa, seja voltado para educaçáo física com caráter social ou técnica, biológica, política, etc.

Ao longo da pesquisa centramos nossa discussão na organização curricular dos cursos de licenciatura e bacharelado em educação física após a reforma curricular (Resoluçóes CNE/CP n. $1^{1}$ e $2 / 2002^{2}$ e $\mathrm{CNE} / \mathrm{CES} \mathrm{n} .7 / 2004^{3}$ ), buscando evidenciar a carga horária destinada para cada área do currículo e se esta caracteriza a prática docente e profissional nos campos específicos das duas formaçóes, haja vista que a reformulação curricular que determinou a separação em licenciatura e bacharelado é muito recente.

Para entendermos a amplitude e complexidade da discussão envolvendo a reforma curricular, tendo como base os dados obtidos e o referencial teórico da área, fizemos um mapeamento das disciplinas e carga horária, as quais foram distribuídas de acordo com as dimensóes do conhecimento (formação ampliada e específica) previstas pela Resoluçáo CNE/CES n.7/2004³.

Em relação às dimensôes do conhecimento utilizadas como recurso para organização das disciplinas em áreas, ressaltamos que a formação específica agrega uma carga horária maior e um 
maior quantitativo de disciplinas, fato já esperado para esse contexto de formação. Nesse sentido, a dimensão cultural do movimento humano, apresentou a maior carga horária para os dois cursos, o que condiz com os preceitos para a formação inicial em educaçáo física, visto que abarca os conhecimentos identificadores como as manifestaçôes e expressôes da cultura do movimento humano nas suas formas de jogos, esportes, ginásticas, danças, lutas, entre outros. $\mathrm{Na}$ sequência, aparecem as dimensôes didático-pedagógica e técnico-instrumental, sendo a primeira mais evidenciada na licenciatura e a segunda no bacharelado, ou seja, demonstrando ênfases diferenciadas na organizaçáo dos conhecimentos tratados nas duas formaçôes. As demais dimensóes que representam a formação ampliada receberam o mesmo grau de importância no que diz respeito às cargas horárias para ambas as formaçóes.

Mediante estes resultados pressupomos que os cursos investigados possuem uma identidade própria relativa que os caracterizam como licenciatura e bacharelado, em especial quando temos a dimensão didático-pedagógica com maior destaque na formação de licenciados e a técnico-instrumental na de bacharéis. Além disso, devido ao fato das mudanças curriculares serem recentes e de não termos tradição de cursos distintos (licenciatura e bacharelado) na área, o processo de construçáo de características próprias para as diferentes formaçôes ainda não está consolidado e, como consequência, "a sensação que se tem é de uma constante "reinvenção da roda", com pouca margem para inovação nos currículos" ${ }^{3}$ (p.426).

Supõem-se dessa forma, que os próximos anos serão decisivos para a legitimação ou não da separação da formação em educação física. Portanto, apontamos que por termos desenhado a realidade dos cursos a partir de um recorte, tendo como base a matriz curricular presente no projeto pedagógico, outros caminhos para constatar a realidade que se efetiva podem complementar o estudo, subsidiando novas discussôes e intervençôes para a área. Assim, entendemos que há necessidade de que seja ampliado o número de trabalhos em relaçáo à formaçáo, sobretudo os que permitam obter dados que possam contribuir para a elaboração de currículos inovadores e que de fato caracterizem as formaçóes da área.

\begin{abstract}
Identity of courses licentiate and bachelors' degree in Physical Education in Parana: an analysis of the areas of knowledge

This descriptive research aimed to identify in the physical education course curriculum the distribution of workload by area of knowledge, in order to understand how the formation is characterized in Paraná, especially regarding the existence of its own characteristics for teaching and bachelors' degree. Thus, we analyzed twenty-eight pedagogical projects through documentary analysis, in which we categorized the disciplines from the curriculum by knowledge's areas/dimensions (specific formation and expanded formation), suggested by the Resolution CNE/CES n.7/2004. Based on the results we could observe that the specific formation results in the highest workload and the biggest quantity of disciplines. The main representative was the culture dimension of the human movement, with the highest workload for both, teachers and bachelor's degree. This result suits the precepts for the basic formation in physical education, since it involves the knowledge identifiers that have historical tradition of the area. We also point that the courses have their own and relative identity that characterize it as a teaching and as a bachelor degree, since the didactic-pedagogic dimension have greater prominence in the training licentiate and technical-instrumental in the bachelor's degree. The dimensions related to extended formation received the same level of importance for both courses. However, we want to emphasize that there is a need of making other researches that can support new discussions and interventions for the area, especially because the curriculum reform that determined the separation between teaching and bachelor degree is very recent.
\end{abstract}

KEY WORDS: Curriculum; Formation; Education; Intervention. 


\section{Referências}

1. Brasil. Conselho Nacional de Educação. Conselho Pleno. Resolução n.1, de 18 de fevereiro de 2002. Institui diretrizes curriculares nacionais para a formação de professores da educação básica, em nível superior, curso de licenciatura, de graduação plena. Diário Oficial da União, Brasília (9 mar. 2002); Sec.1:31.

2. Brasil. Conselho Nacional de Educaçáo. Conselho Pleno. Resoluçáo n.2, de 19 de fevereiro de 2002. Institui a duração e a carga horária dos cursos de licenciatura, de graduação plena, de formação de professores da educaçáo básica em nível superior. Diário Oficial da União, Brasília (4 mar. 2002); Sec.1:9.

3. Brasil. Conselho Nacional de Educação. Câmara de Educação Superior. Resolução n.7, de 31 de março de 2004. Institui as diretrizes curriculares nacionais para os cursos de graduação em educação física, em nível superior de graduação plena. Diário Oficial da União, Brasília (5 abr. 2004); Sec.1:18.

4. Gimeno Sacristán J. O currículo: uma reflexão sobre a prática. Porto Alegre: Artmed; 2000.

5. Apple MW. Ideologia e currículo. 3a ed. Porto Alegre: Artmed; 2006.

6. Gimeno Sacristán J, organizador. Saberes e incertezas sobre o currículo. Porto Alegre: Penso; 2013.

7. Marcon D, Graça ABS, Nascimento JV. Critérios para a implementação de práticas pedagógicas na formação inicial em educação física e implicaçôes no conhecimento pedagógico do conteúdo dos futuros professores. Rev Bras Educ Fís Esporte. 2011;25;3:497-511.

8. Brasil. Conselho Nacional de Educação. Câmara de Educação Superior. Resolução n.4, de 6 de abril de 2009. Dispóe sobre carga horária mínima e procedimentos relativos à integralização e duração dos cursos de graduação em biomedicina, ciências biológicas, educação física, enfermagem, farmácia, fisioterapia, fonoaudiologia, nutrição e terapia ocupacional, bacharelados, na modalidade presencial. Diário Oficial da União, Brasília (7 abr. 2009); Sec.1:27.

9. Oliveira AAB. A formaçáo profissional em educaçáo física: legislação, limites e possibilidades. In: Souza Neto $S$, Hunger D, organizadores. Formação profissional em educação física: estudos e pesquisas. Rio Claro: Biblioética; 2006.

10. Freire ES, Verenguer RCG. Estágio supervisionado: a nova proposta para o curso de bacharelado em educação física da Universidade Presbiteriana Mackenzie. Rev Mackenzie Educ Fís Esporte. 2007;6:115-9.

11. Martins CB, Brandalise MAT. Formação de professores na perspectiva de desenvolvimento profissional e organizacional da escola. Ling Educ Soc. 2007;12:21-8.

12. Silva SAPS, Souza CAF, Checa FM. Situação do estágio supervisionado em IES privadas da grande São Paulo. Motriz. 2010;16:682-8.

13. Hunger D, Nascimento JV, Barros MVG, Hallal PC. A trajetória dos cursos de graduação na saúde: educação física. In: Haddad AE, Pierantoni CR, Ristoff D, Xavier IM, Goilo J, Silva LB, organizadores. A trajetória dos cursos de graduação na saúde 1991-2004. Brasília: INEP; 2006.

14. Anderáos M. A reorganização profissional em educação física no Brasil: aspectos históricos significativos [tese]. Campinas(SP): Universidade Estadual de Campinas, Faculdade de Educação Física; 2005.

15. Gil AC. Como elaborar projetos de pesquisa. 4a ed. São Paulo: Atlas; 2007.

16. Brasil. Ministério da Educação e Cultura. Instituiçóes de educação superior e cursos cadastrados. Brasília: MEC; 2011. Disponível em: <http://emec.mec.gov.br/>.

17. Silva JB. Análise das relações existentes na legislação que orienta a formação profissional dos especialistas em educação física e desportos e os planos nacionais nas áreas educacional e desportiva no Brasil [dissertação]. São Paulo(SP): Universidade de São Paulo, Escola de Educação Física; 1983.

18. Brasil. Conselho Federal de Educação. Resolução n.3, de 16 de junho de 1987. Fixa os mínimos de conteúdo e duração a serem observados nos cursos de graduação em educação física (bacharelado e/ou licenciatura plena). Diário Oficial da União, Brasília (10 set. 1987). Sec.1:38.

19. Tani G. Pesquisa e pós-graduação em educação física. In: Passos, SCE, organizador. Educação física e esportes na universidade. Brasília: MEC; 1988. p.379-94.

20. Soares CL, Taffarel C, Varjal E, Castellani Filho L, Escobar M, Bracht V. Metodologia do ensino da educação física. São Paulo: Cortez; 1992.

21. Bracht V. Educação física e ciência: cenas de um casamento (in)feliz. Ijuí: Ed. Unijuí; 1999.

22. Betti M. Educação física escolar: ensino e pesquisa-ação. Ijuí: Ed. Unijuí; 2009.

23. Soares CL. Educação física escolar: conhecimento e especificidade. Rev Paul Educ Fís. 1996;2:6-12.

24. Marcon D, Graça ABS, Nascimento JV. Formaçáo inicial em educação física, legislação e conhecimentos docentes: interfaces e possíveis perspectivas. In: Souza Neto S, Hunger D, organizadores. Construçấo da identidade profissional em educação física: da formação à intervenção. Florianópolis: UDESC; 2012. p.396-422. 
Pizani J \& Barbosa-Rinaldi IP.

25. Paraná. Secretaria de Estado da Educação. Diretrizes curriculares da educação básica: educação física. Curitiba; SEE; 2008.

26. Pimenta SG. Formação de professores: identidade e saberes da docência. In: Pimenta SG, organizadora. Saberes pedagógicos e atividade docente. São Paulo: Cortez;1999.

27. García CM. A formação de professores: novas perspectivas baseadas na investigação sobre o pensamento do professor. In: Nóvoa A, organizador. Os professores e a sua formação. Lisboa: Dom Quixote; 1992.

28. Tardif M. Saberes docentes e formação profissional. Petrópolis: Vozes; 2002.

29. Reali AMMR; Mizukami MG, organizadores. Formação de professores, práticas pedagógicas e escola. São Carlos: EdUFSCar; 2002.

30. Zeichner KM. Rethinking the connections between campus courses and fi eld experiences in college-and universitybased teacher education. J Teac Educ. 2010;61:89-100.

31. Ferraz OL, Correia WR. Teorias curriculares, perspectivas teóricas em educação física escolar e implicaçóes para a formação docente. Rev Bras Educ Fís Esporte. 2012;26:531-40.

32. Souza Neto S, Alegre NA, Hunger D, Pereira JM. A formação do profissional de educação física no Brasil: uma história sob a perspectiva da legislação federal no século XX. Rev Bras Ciênc Esporte. 2004;25:113-28.

33. Nascimento JV. Formação do profissional de educação física e as novas diretrizes: reflexóes sobre a restruturação curricular. In: Souza Neto S, Hunger D, organizadores. Formação profissional em educação física: estudos e pesquisas. Rio Claro: Biblioética; 2006.

34. Barros JMC. Educação física na UNESP de Rio Claro: bacharelado e licenciatura. Motriz. 1995;1:71-80.

35. Bagrichevcki M, Palma A. Questionamentos e incertezas acerca do estatuto científico da saúde: um debate necessário na educação física. Rev Educ Fís. 2004;15:57-66.

36. Nogueira L, Palma A. Reflexôes acerca das políticas de promoção de atividade física e saúde: uma questão histórica. Rev Bras Ciênc Esporte. 2003;24:103-19.

37. Devide FP. Educação física, qualidade de vida e saúde: campos de intersecção e reflexôes sobre a intervenção. Rev Mov. 2002;8:77-84.

38. Devide FP. A educação física escolar como via de educação para a saúde. In: Bagrichevsky M, Palma A, Estevão A, organizadores. A saúde em debate na educação física. Blumenau: Edibes; 2003. p.137-50.

39. Brasil. Conselho Nacional de Educação. Câmara de Ensino Superior. Parecer n. 215, de 11 de março de 1987. "Reestruturação dos cursos de graduação em educação física, sua nova caracterização, mínimos de duração e conteúdo. Diário Oficial da União, Brasília (11 mar. 1987).

40. Kokobun E. Pós-graduação em educação física no Brasil: indicadores objetivos dos desafios e das perspectivas. Rev Bras Educ Fís Esporte. 2003;24:9-26.

41. Demo P. Pesquisa e construçáo do conhecimento: metodologia científica no caminho de Habermas. Rio de Janeiro: Tempo Brasileiro; 1997.

42. Barbosa-Rinaldi IP. A ginástica como área de conhecimento na formação profissional em educação física: encaminhamentos para uma reestruturação curricular [tese]. Campinas(SP): Universidade Estadual de Campinas, Faculdade de Educação Física; 2004.

43. Soriano JB; Silva PM; Calciolari Junior, A. A educação física enquanto grupo profissional: algumas inquietaçóes sobre formação e intervenção na área. In: Souza Neto S, Hunger D, organizadores. Construção da identidade profissional em educação física: da formação à intervenção. Florianópolis: UDESC; 2012. p.423-45.

\section{Agradecimentos}

O texto é proveniente de dissertação de mestrado desenvolvida a partir do Projeto de Pesquisa apresentado ao Edital MCT/Conselho Nacional de Pesquisa (CNPQ), n.14/2009 - Universal.

ENDEREÇO

Juliana Pizani

R. Tietê, 222 - apto. 203

87020-210 - Maringá - PR - BRASIL e-mail: jupizani@hotmail.com
Recebido para publicação: 08/07/2013

1a. Revisão: 23/07/2013

2a. Revisão: 14/05/2014

Aceito: 12/09/2014

682 • Rev Bras Educ Fís Esporte, (São Paulo) 2014 Out-Dez; 28(4):671-82 